荣祭和物留励投給为國家作出重要貢献的科学 工作者。

中國科学院研究所暫行獎劯办法規定, 研究 所的工作人員合乎下列条件之一的給予獎励:

1. 按計划完成科学研究工作任务, 其工作成 樍优良，在科学上或國民經济上有重要价值的;

2. 完成的科学著作 (或經典譯著), 在科学上 或对生堂上有重大意义的;

3. 对技衍性的輔助工作和研究方法、仪器、 工具的改進工作住紈著成績的;

4. 在培养幹部方面有顯著成續的;

5. 在行政工作方面有顯著成績的。

研笔所奖励分集体和个人兩种，每种分三 等。等体一等獎獎給獎金 1,500 元，二等獎獎金
1,000 元, 三等獎獎金 500 元; 个人一等獎獎給

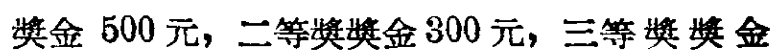
100 元。

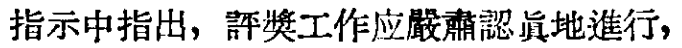
切实掌握獎励标准, 要防止獎励面过筧的平均主 义偏向, 也要防止獎励面过塽而失去了獎励作 用; 結合獎励工作应萓傅科学工作人員創造性劳 动对于國家建設和加速科学發展的作用, 宣傅先 進事迹, 樹立学㚙榜样, 达到通过獎励鼓舞全体 工作人員前進的目的。

此外, 对有关進行獎励的一些其他問題地作 了規定。

\section{〔史 超〕}

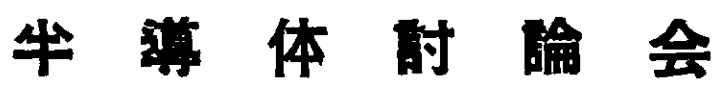 \\ 王守武
}

（中國科学院应用物理研究所）

中國物理学会为了把近年本有迅速登的牛 运休科学技術席泛地介紹給我國的物理学工作 者, 在今年 1 月30日至 2 月 4 日召开了牛導体討 論会。参加会議的除了物理学会的会員外还有各 研究机構、紊部門和高等学校的有关的科学工 作者。会議的月的主要是一般地介紹牛導体的各 种特性。

在这次会議中，一般介紹性的报告共有十次， 宣境的工作报告共有 5 篇; 此外，对如何在我國 迅速开展牛学体科学技衡砳究工作也進行了座 歇。

討論会的第一天，应用物理研究所洪朝生向 到会者作了半導体的一般介紹性的报告。这报告 的主要目的是对一些以前不很了解牛導体的听众 介紹一下牛導体的基本性質和用途, 为了解以后 各項报告打下基礎。

关于牛導体整流器方面的一般介紹性报告有 2次。首先由应用物理研究所王守武报告牛導体 的整流效应。他在簡單地說明了牛導体整流的原
理之后, 接着提出了一个良好的整流器所应䜾具 备的五項条件。他渷新式的銷整流器基本上是滿 足这 5 項条件的。鍺整流器是由n 型鍺 (电子導 电的鍺）和 $\mathrm{p}$ 型鍺（空究導电的鍺）接合在一起

（簡称 $p-n$ 結）而成的。它的正方向电 阻 可以 和直流發电机相比, 但是它的反方向电流和 反

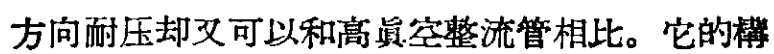
造和硒整流器一样簡單, 而它的制造成本却文很 便宜。报告最后指出, 鍺整流器还不能算是十公 十美的。为了要得到更好的坐導体整流器, 所用 的材料应該有更大的禁帶寬度，較少的复合中心。 同时一个良好的牛導体整流器的構造应硋是在低 电阻的 $\mathrm{n}$ 型和 $\mathrm{p}$ 型牛導体之間, 还有一愿很溥的 高电阻的（很純的）牛導体。

关于整流效应的另一項报告是高鼎三的 “鍺 整流器的制造問題”。这报告的主要內容是他在 1958 年至 1955 年間在美國所做的工作。报告中 叙述了如何用什質擴散的方法制造鍺的 $\mathrm{p}-\mathrm{n}$ 結。 他所用的 $\mathrm{p}$ 型什質是锗， $\mathrm{n}$ 型什質是唋。他著量

3 月号

科学通报 
指出, 制造大功爽鍺䇥流器的主要困难是要使什 質摭散進入牛运体的援散陣面很平。高鼎三經过 深入研究之后, 最后采取了使熔化的鉛滴在鏙表 面上的方法。結果滿意地解决了控散陣面不平的 困难。高鼎三制成的 150 安培耐 压 66 伏的鍺整 流器, 其大小只有牛个㖊头那么大。他最后在报 告中把鍺整流器和硒整流器在各种性能和成本方 面作了比較, 明确地指出了踷整流器的优越性。 高鼎三的报告生动地描述了制造过程中的每一步

祭, 因而引起了㧥業部門極大的兴趣。

关于牛對体放大器方面的一般介釈性报告也 有 2 次。首先由北京大学黄昆报告牛導体的放大 作用。费昆在說明結型放大器的基本原理之后, 接 着討諭了結型放大器結構与性能閒的关系。他着 更指出，基板本身的电阻是限制制造大功秉放大 器的主要因素, 而集电結本身的电容, 以及由于 少数載流者在基板中的擴散时間所引起的擴散电 容却是限制放大器使用于更高頻率的主要原因。 最后, 黄昆还提出了其他各种类型牛導体放大器 的構造及其简單工作原理。这些放大器郖是在結 型放大器的基礎上的進一步的改淮, 它們苓可能 应用到更高的頻爽范園。黃昆的报告吸引了最多 的听众, 这锐明了各方面对牛導体放大器的重 䤄。

关于放大器的另一資报告是成众志的 “踷放 大器的应用問题”。他首先介紹了現有的各种类 型的坐導体的放大器。特别引人注意的是目前牛

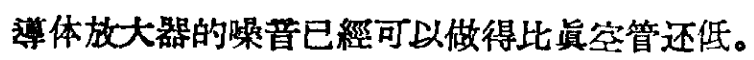
在实驗空中，牛導体放大器应用的頻栾范圍已經 可以达到 1,000 兆周, 而千瓦以上的坐導体 放大 器也已在研究之中。接着, 他介紹了出留体放大

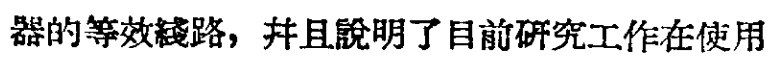
頻率、使用功率和噪晋問題等各方面的發度情况 以及佮待解决的問題。

有关牛學体光学性方方面的一般介紹性报告 有 3 次。应用物理研究所湯定元报告了牛導体的 光电效应。牛拿体的光电效应大致上可分为 3

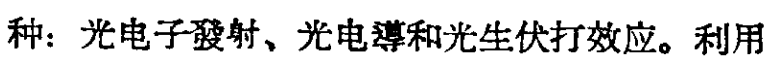
第一种效应制成的器件为光电管，利用第二种效 应的为光敏电阻，利用第三种效应的为光电池。 这三种牛導体器件在应用时的主要性能决定于它 們的灵敏度、弛像时間和光譜分布。湯定元介紹
了各种光电管、光敏电阻和光电他的上迅 3 种特 性。这报告的中心部分是介紹光电薄的基本原理, 还扼要地敘述了光生伏打效应的理諭及其投展情 况.

光学性方方面的另外雨个报告是关于固体 光的。首先由应用物理研究所部少鸿作洞体㖟光 的一般介紹。他在談到發光的基本特征时着重指 出: 对發光体的基本特征的研究工作，目前絕大 多数是針对着發光体的各种用途而做的。因此对 磁光体的电学性質的研究做得很少, 而对它的光

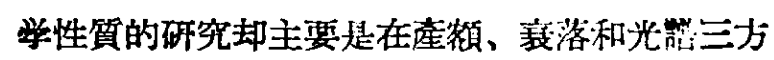
面進行3 其中只有对衰落的㸴究工作, 是自前唯 一已經得到比較肯定的普淈結渝的。最后, 許少 鸿在提到發光材料时說, 目前發光材料的实际制 备技術已远远跑在理論的前面。如果半綮体的理 論可以發晨得很快, 則对發光材料的制备和研究 是会起很大作用的。另一方面由于狆光材料伿要

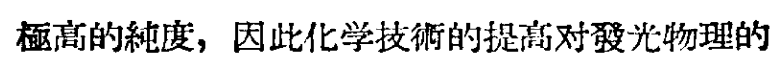
展也是有重大新义的。

固体光光面的另一个报告是应用物㫜研究

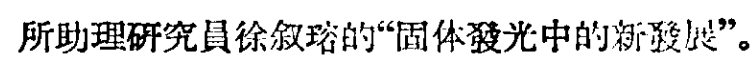

在这个报告中，徐叙瑢渚重介紹了新近要到正酒 的电致發光現象。电致發光是把發光材料放在艾 变电埸中直接發光的現象。目前已經可以利用这 个現象制造出各种完度的灯, 这些出的效兆现在 虽然还是很低，但是由于它們的器光机構是㨁接 把电能变为光能，在原则上它們的效等是一定可 以提得很高的。因此这方面的發等侍很大的游途。

一般介紹性报告山还有雨篇召门人注悹的报 告: 周光地的“牛薄体村料”和诰朝生的“能量轉 換”。周光地比較詳䋨地討訟了 C、Se、Ge、Si 四 种元素的电学性筫, 抹指出碳化物和铻化物往往 都是牛薄体，它們在工業上的用途是不应該被忽 親的。他还談到氧化物、硫化物、硒化物和碇化 物，指出这方面有許多是我們很熟悉㧫又常用到 的牛導体材料，例如 $\mathrm{Cu}_{2} \mathrm{O}$ 的整流器, $\mathrm{CdS}$ 、 $\mathrm{PbS} 、 \mathrm{PbSe}$ 和 $\mathrm{PbTe}$ 的光敏电阻, $\mathrm{BaO} / \mathrm{SrO}$ 的热电子發射陰極, $\mathrm{ZnS}$ 的策光板等。此外, 他 还提到了許多比較复雜的本導体化合物，例如筮

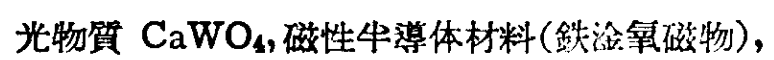
铁电性材料 $\mathrm{BaTiO}_{3}$ 等。最后, 他锣还 有一項 特別令人注意的牛導体材料最近正在到展起來, 
这就是金凰間化合物牛導体。猿光地在这方面曾 做过一些研究工作，他在会議的論文集中报道了 他工作的結喿。洪朝生在能量轉換的报告中首先 介紹了利用牛等体發电的各科可能的能 量轉 換 器。原理上这些能量轉換器可以分为兩类, 第一 类是利用温差电效应來發电的，第二类是利用 p-n 結吸收輻射或高能粒子而被电的。前一类牛 晸体發电机在荻联已正式生产，供農村中作中小 型功率的电源之用。后一类牛導体發电机还可以 分为兩种, 一种是吸收光能來發电的, 它們可以 作为日光电池，其效爽可达 11\%。另一种是吸收 高速电子來發电的, 它們可以作为原子能电池, 但目前效筞还很低。湝朝生接着介紹了这些牛導

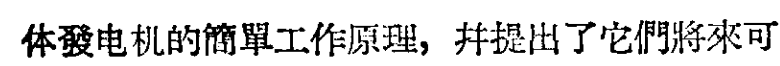
能墢展的方向。

以上报告的講稿正在整理中，不久將以專集 的形式出版。

在会議上宣謮的 5 篇工作报告是:

1. 王守武的 “牛導体的电子生伙打效应的理 铪”。在这工作中，作考詳細地計算了在弱的高 速电子注霜击下，具有阻擋層的坐導体光电他所 座生的次級电动势; 抹且討諭了次級电动势随电 子注能量改变的曲綫。最后，作者把理諭曲綫和 实驗数据作了比較, 扭对比較結柴作了詳尽的討 諭。

2. 陈志全的“氧化亞銅整流器特性受拉力的 影响”。在这工作中，作者把氧化亞銅整流器做成 像材料試驗机上所用的受拉試驗样品的形式，加 上逐步增加的拉应力。在受拉試驗的过程中，作 者同时測量了整流器的直流特性曲綫和等 效电 容。測量的結果表明：拉力对阻擋愿的破坏有一 定的臨界点。在这臨界点以前，破坏抹不發生。 这破坏的進行过程是緩慢的（若千分鐘严若干小 时)，同时又是局部的，它可能只在边䋑上發生。

3. 曹昌視的 “ $\mathrm{Cu}_{2} \mathrm{O}$ 整流器中形成 $\mathrm{n}$ 型局的 可能解釋”。在这工作中，作者假定銅在高温氧化 过程中, $\mathrm{Cu}_{2} \mathrm{O}$ 厚与銅片接触的一面近似地达到 与銅片本衡的狀态。同时放虑到在高温下 $\mathrm{Cu}_{2} \mathrm{O}$ 中电子的費密能級应該接近于禁帶的中部，因而 在接近与銅片接触处的 $\mathrm{Cu}_{2} \mathrm{O}$ 層內, 应該有正的 空間电荷出現。在这种情况下，作者解釋了在与 銅片接触处的 $\mathrm{Cu}_{2} \mathrm{O}$ 內形成含銅过多的可能性。
4. 趙廣增、徐世秋、王傳的“硫化鎘單晶体 中的激开光偝”。在这工作中, 作者在液态空气温 度下, 研究薄的 CdS 單晶对偏振光的吸收。結 果發現在 CdS 晶体本征吸收边附近, 有七条强 的綫組成的一个类㑹光譜出現。这些譄綫中每一 条的波数都滿足下列关系

$$
\begin{gathered}
\nu_{k}=20270-\frac{11754}{k^{2}}(\text { 厘米) }-1 \\
k=3,4,5 \cdots \cdots 9 .
\end{gathered}
$$

最后，作者对这些結果作了詳細的討諭。

5. 湯定元、周㺩先的 “一种硫化鉛光敏电阻 的制备”。在这工作中，作者描述了一利硫化鉛溥 膜光敏电阻的制造方法。这种制法比較簡單，同 时得到的成品性能上也是滿意的。

会議中的另一項活动是座談会。座談会开始 时先由徐叙瑢报告了参加苏联第八次全苏坐導体 会議的經过。接着, 会議就如何在中國迅速开展 牛導体科学技術研究工作進行了座談。在發言中, 大家一致認为在祖國的社会主义建設中, 开竖나 覒体科学技術的硑究工作是非常重要的、迫切的, 而且也是完全可能的。

在会議的总結会上, 全体一致通过了一項决 議。决議中提出了下列几項建議:

1. 請中國科学院迅速召开包括与体導体有关 各部門的牛導体工作会議, 進行討論, 为綜合制 定全國牛導体科学發展远景計划及早准备条件。

2. 在科学院系統中立即放慮筹建綜合性4运 体研究所, 作为生導体科学及技䢙發厝的基地。

3. 首先在綜合大学物理系重点設立牛導体事

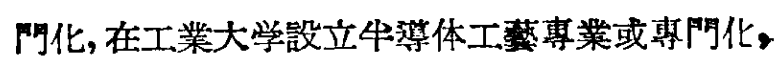
井在有关的学科中增开牛導体的課程。

4. 在建立基地和培美幹部的工作中，应充分 發捙各方面現有的潜在力量, 扭对一切有条件:在 牛導体方面進行工作的人才給予積極的授助与指 渑。

5. 在進行牛導体学科全面規划的同时, 有关 工業部門应立刻筹建出導体工厂，先用國外原料 生産牛導体器件, 丰通过工厂生産培养幹部。

6. 有关碳冶、化工等部門应迅速設法解决原 料來源問題, 以便大規模生產各項牛導体器件。

7. 和牛緮体工作有关的科学工作者应廣泛地 开展牛導体科学技術的宣傳工作，使牛導体的知 識深入群众, 以利工作的开展。 